\title{
Can One Hang on Kneeling with Tied-Leg and Mouth?
}

\author{
Sabyasachi Nath* and HK Pratihari \\ State Forensic Science Laboratory, Tripura, India
}

*Corresponding author: Sabyasachi Nath, State Forensic Science Laboratory, Tripura, 799015, India, Tel: +919436454651, E-mail: drsabyasachinath@gmail.com

Citation: Sabyasachi Nath, HK Pratihari (2018) Can One Hang on Kneeling with Tied-Leg and Mouth? J Forensic Crime Stu 2: 201

Article history: Received: 07 March 2018, Accepted: 18 May 2018, Published: 22 May 2018

\begin{abstract}
There are various means adopted for suicide. Poisoning and hanging are reported to be very common means to end life by oneself. As per National Crime Records Bureau (NCRB), MHA, Government of India, 45.6\% hanging cases were reported out of total suicide cases registered in India in the year 2015. In one case, the victim age about 36-year committed suicide due to family feud and hanged on kneeling with tied leg and mouth near the residential place showing unusual criminal profile. The analysis of undisturbed crime scene and reconstruction of course of events supported by autopsy findings could conclusively prove to be a case of partial suicidal hanging. The hanging evidence was initially unbelievable to the relatives, investigating officer and in public view with unusual criminal profile in this case. The details have been discussed in this paper.
\end{abstract}

Keywords: Suicidal hanging; Kneeling; Tied-Leg; Tied-Mouth; Autopsy Study; Psychological Behavior

\section{Introduction}

Suicide is among the three leading causes of death among people aged 15-44 years in some countries and the second-leading cause of death among those aged 10-24 years [1]. India has the highest suicide rate in the world among the youth [2]. In every year, more than 800,000 people commit suicide around the globe of which 135,000 (17\%) are from India having $17.5 \%$ of world population $[3,4]$. Here, the suicide rate has increased from 7.9 to 10.3 per 100,000 people in last two decades with higher suicide rates in southern and eastern regions $[5,6]$. The reason for such high numbers can be attributed to lack of economic, social and emotional resources, more specifically, academic pressure, workplace stress, social pressures, modernization of urban centers, relationship concerns and the breakdown of support systems [2]. There are several risk factors that may be responsible for a suicidal attempt or completion of suicide. Some of those factors are capsulized in (Figure 1) [2,7,8].

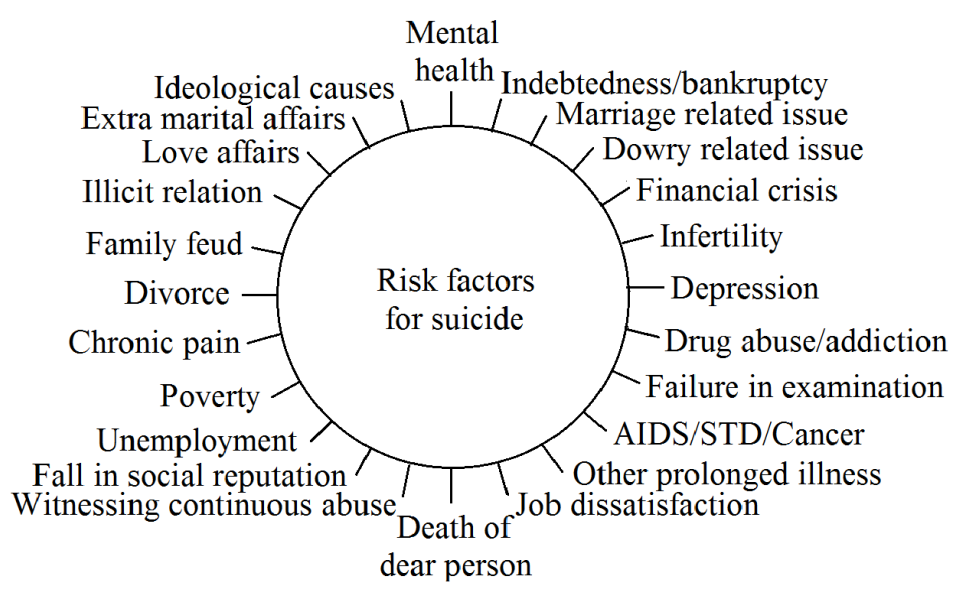

Figure 1: Risk factors for suicide

On an average one person commits suicide in every four minutes in India [9]. The crime clock on suicide is very alarming and menace to the society. As per National Crime Record Bureau (NCRB), MHA, Govt. of India, 60,952 persons committed suicide by hanging in the year 2015 and this number contributes about $45.6 \%$ to total suicide cases in India. There are various methods 
of killing oneself, but suicidal hanging is preferable since it is almost painless. It takes very less time to end life and easy to locate place (indoor/outdoor) as well as commonly available hanging materials like rope, napkin, saree, dupatta, dhuti (long cloth), etc. [10]. Further it is seen that different methods are used by the victim manifesting following psychological behavior in the process of hanging $[8,11-14]$ :

- Close the eyes/face with napkin to avoid fear of death,

- Close the mouth to suppress groaning sound during pain and despair,

- Tie both hands behind by napkin/handkerchief/towel/belt to prevent self defense,

- Tie legs to prevent support from nearby object,

- Tie with 'dupatta' (long cloth) together in love pact suicide to remain inseparable ever,

- Tie tag on the wrist showing name, address etc. for easy identity at unknown place,

- Suicide notes stating nobody/or someone responsible for death,

- Adding body weight by tying bag full of books in hand to enforce constriction,

- Drugging/hanging together to ensure death,

- Self inflicted injuries failing by suicidal hanging,

- Gagging of mouth with cloth.

The victim in this case committed partial suicidal hanging on kneeling position leaning his head downward. Further, the criminal profile is also very unusual since the victim tied his leg and mouth with pieces of cloth. Such type of psychological behavior during the preparation of hanging is rare and sufficient reference is not available in literature.

\section{Case report}

The victim was a married male person age about 36-year. He used to work as a daily laborer and managed his livelihood with hardship. The economic condition of the victim was poor and relation with wife was also not good resulting frequent family feud. Consequently the victim was suffering from depression. One evening, quarrel took place between the victim and his wife with some familial issue. After a while, he left home and did not return back that night. On the very next morning, the deceased was found in partial hanging condition from a bamboo-beam of an abandoned house nearby his home. The economic condition coupled with conjugal relation with wife manifested to suicidal hanging in an unusual and unbelievable way which is a punishable offence under section 309 of IPC (Indian Penal Code). Investigation by the police revealed no other issue like religious, political, personal enmity, was involved in the suicidal decision in this case.

\section{Observation}

The unusual methods adopted by the victim are shown in Figure 2-6.

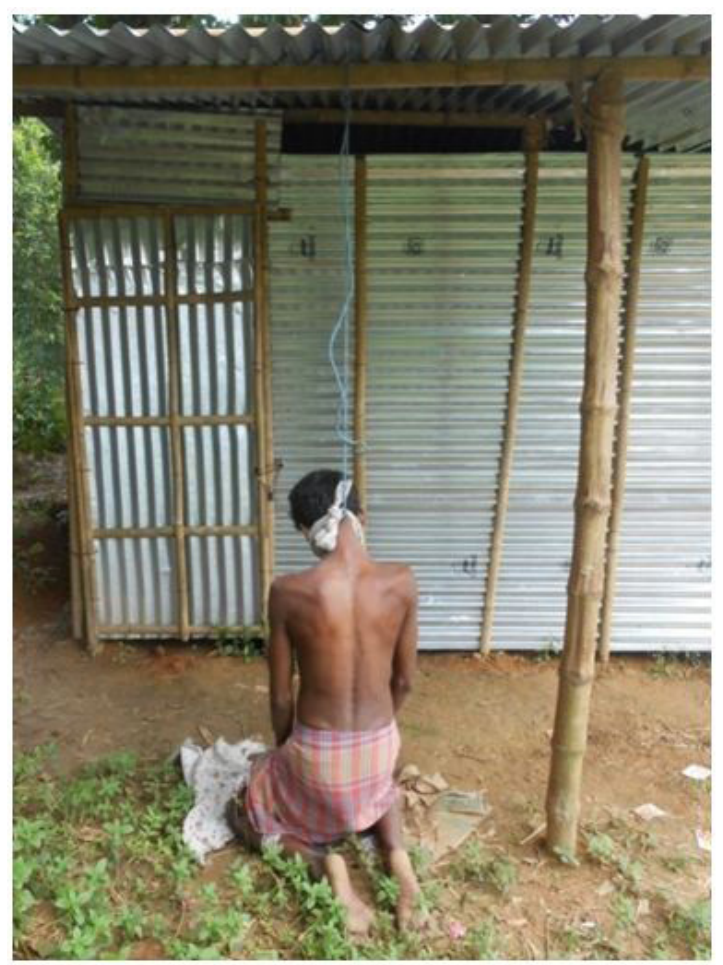

Figure 2: Victim hanged on kneeling with a nylon rope from a bamboo beam. The total length of the rope is $220 \mathrm{~cm}$ and the length between the suspension point and the ligature knot around the neck is $100 \mathrm{~cm}$, the rest part of the rope being freely suspended from the suspension point 


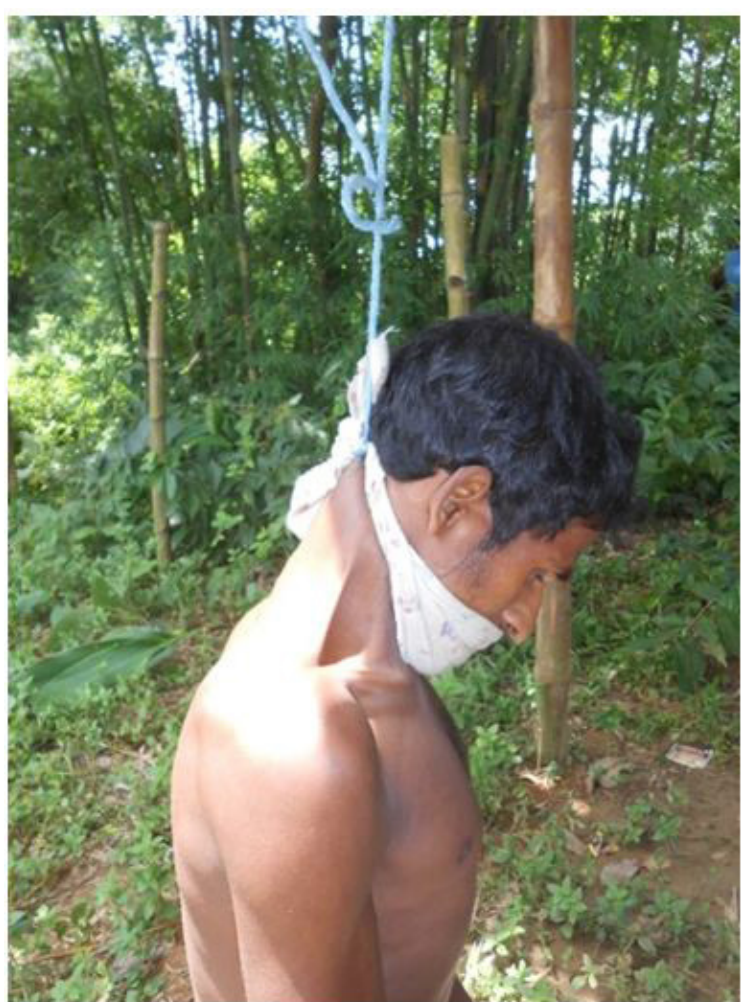

Figure 3: Victim hanged with tied-mouth with a piece of white cloth to suppress groaning sound during pain/despair

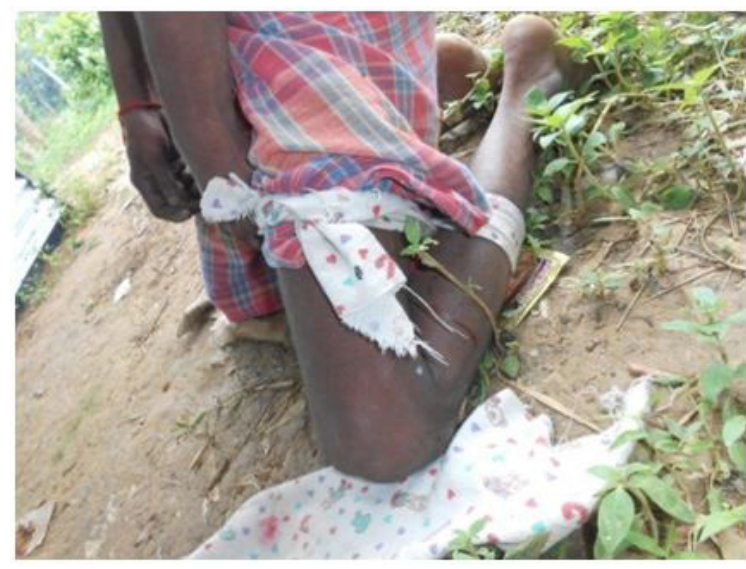

Figure 4: Victim hanged with tied-leg on kneeling position to prevent support from any nearby object. This was done to ensure that he does not attempt to rescue himself

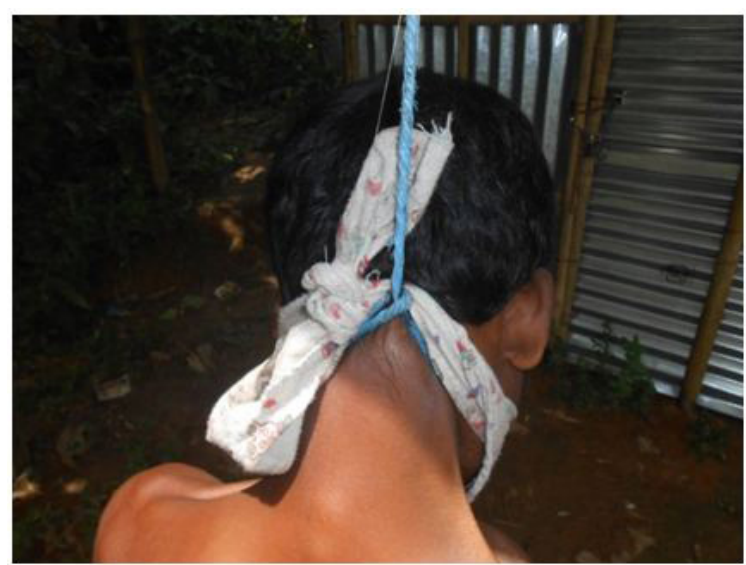

Figure 5: Tied-mouth from back showing slip knot of nylon rope (hanging material) 


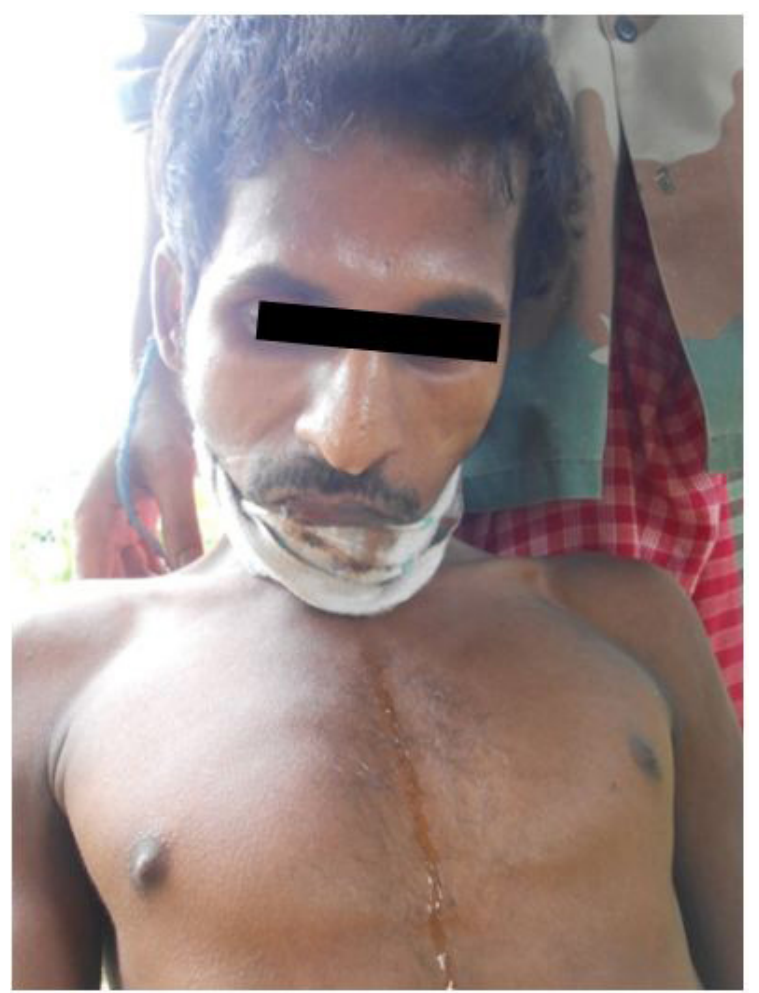

Figure 6: Showing pale face, protruded tongue and dribbling of saliva which are the commonest symptoms of asphyxial death (photograph was taken after removal of cloth from the mouth)

\section{Autopsy Findings}

\section{External}

The deceased was a 36-year old male, $151 \mathrm{~cm}$ in height, $54 \mathrm{~kg}$ in weight of average built. The mouth and both the eyes of the victim were partially open; tongue was bitten in between teeth; there was cyanosis in lips, mucous membrane of mouth, nail etc.; one blue color nylon rope was found tied around the neck with slipping knot; one white color piece of cloth was found tied around the mid part of his left leg, $20 \mathrm{~cm}$ below the knee. One dark brown color, obliquely placed, continuous, grooved, parchmentised ligature mark was present around the neck, situated $2.6 \mathrm{~cm}$ below the right mastoid bone, $6 \mathrm{~cm}$ below the left mastoid bone, $4.5 \mathrm{~cm}$ below the chin and $10 \mathrm{~cm}$ above the suprasternal notch. The total neck circumference was $31 \mathrm{~cm}$. Maximum width of the ligature mark was $1 \mathrm{~cm}$. Rigor mortis was present all over the body. No sign of putrefaction was present during post mortem examination.

\section{Internal}

On dissection of neck, the subcutaneous area underneath the ligature mark was found glistening white with ecchymosed margins. Larynx, trachea, thyroid cartilage, hyoid bone and carotid arteries were found intact. Above mentioned ligature mark was antemortem in nature and age of this mark was fresh at the time of death. Brain was congested and edematous. Nasal mucosa, larynx, diaphragm, esophagus, trachea, bronchi, both the lungs and heart were found congested. Petechae were found in the interlobular areas of both the lungs. No abnormalities were detected in pleural cavities, large blood vessels, abdominal wall, peritoneal cavities, small intestine, large intestine, vermiform appendix, mesentery, pancreas, liver, gall bladder, biliary passages, spleen, kidney, renal pelvis, ureters, pelvic walls, urinary bladder, urethra and genital organ. The toxicological analysis of viscera and body fluid ruled out the presence of any poison and drug in this case. The cause of death was asphyxia due to hanging.

\section{Discussion}

This is a unique case of partial hanging and such case of hanging on kneeling position with tied leg/mouth initially created doubt to be homicidal hanging. But examination of undisturbed crime scene like absence of any sign of dragging of the body on the ground nearby the crime spot, external post mortem symptoms like inverted V-shaped ligature mark, protruded tongue, dribbling of saliva, involuntary discharge of semen, pale face, cyanosis on finger nail and other parts of the body, absence of any other injury observed on the body of the victim along with autopsy report could conclusively prove to be a case of suicidal hanging. Further, in this case the criminal profile and psychological behavior before hanging was unique and tying of leg was done to avoid external support and mouth was closed to suppress groaning sound usually produced in pain/despair in the process of hanging. Thus the possibility of homicide could be ruled out in this case. 
Acknowledgement

The authors are thankful to the autopsy surgeon for providing supportive documents and also to Dr. A. Pal for his assistance.

\section{References}

1. World Health Organization Report, "Suicide Prevention" (2009).

2. The MINDS Foundation (2017) India Has the Highest Suicide Rate Among Youth. Here’s How You Can Help Someone Who's Struggling. The Better India, India

3. Suicide prevention (SUPRE) World Health Organization (2012).

4. Suicides in India (2012) Archived 2014-05-13 at the Wayback Machine. The Registrar General of India, Government of India.

5. Vijaykumar L (2007) Suicide and its prevention: the urgent need in India. Indian J Psychiatry 49: 81-4.

6. Polgreen Lydia (2010) Suicides, some for separatist cause, Jolt India. The New York Times.

7. Suicide in India. Wikipedia.

8. Choudhury S, Pal A, Das RK, Pratihari HK (2017) Hanging of Blind Man. J. Forensic Sci Criminal Inves 4: 1-3.

9. Crime in India (2015) National Crime Records Bureau, Ministry of Home Affairs, Government of India.

10. Pal A, Pratihari HK (2017) Unusual Hanging-A Case report. J Forensic Cri Stu 1: 102: 1-5.

11. Pal A, Pratihari HK (2018) Suicide Pact of Love Couple- A Case report, J. Forensic Sci \& Criminal Inves 7: 1-3.

12. Sikary AK, Behera C, Murty OP, Rautji R (2016) Hand Tied With Bag Full of Books in Suicidal Hanging, J Forensic Sci 61: S265-7.

13. Nath S, Pratihari HK (2018) A Peculiar Case of Hanging - A Case Report, J. Forensic Sci Criminal Inves 8: 1-3.

14. Alexander McQueen hanged himself after taking drugs (2010) The Guardian News and Media Limited. 